\title{
Ocena jakości warstw wierzchnich nanometalicznych napawanych GMA w sposób zrobotyzowany na powierzchniach krzywek przesiewacza koksu ze stali Hardox 400
}

\author{
Evaluation of the quality of nano-metallic surface layers \\ produced by robotic GMA cladding on cams of coke screening \\ plant made of Hardox 400 steel
}

\section{Streszczenie}

Przedmiotem badań była analiza wpływu parametrów procesu zrobotyzowanego napawania GMA drutem rdzeniowym EnDOtec DO390N o średnicy 1,6 mm powierzchni roboczych krzywek przesiewacza koksu ze stali trudnościeralnej Hardox 400 na jakość, kształt i odporność na zużycie ścierne napoin. Próby technologiczne napawania prowadzono na stanowisku wyposażonym w robota spawalniczego Reis SRV6 oraz synergiczne urządzenie spawalnicze TotalArc 5000. Badania wykazały, iż napoiny próbne wykonane drutem rdzeniowym EnDOtec DO390N posiadają osnowę metaliczną na bazie żelaza z wydzieleniami węglików boru o znacznej dyspersji, równomiernie rozłożonymi w osnowie. Wielkość zarówno węglików boru, jak i niektórych składników fazowych nie przekracza 1,0 $\mu \mathrm{m}$, a udział faz o tak niewielkiej wielkości w napoinie wynosi co najmniej $30 \%$, zależnie od parametrów napawania. W związku z tym napoiny próbne wykazują cechy materiału metalicznego nanostrukturalnego. Pomimo wysokiej twardości ok. 62 do 64 HRC, napoiny cechują się nieznaczną skłonnością do pękania w warunkach, w jakich prowadzono próby napawania zrobotyzowanego GMA. Badania odporność na zużycie ścierne typu metal-metal wykonane za pomocą próby ball-on-plate wykazały, że napoiny próbne posiadają prawie siedmiokrotnie wyższą odporność na zużycie w porównaniu do stali Hardox 400.

Słowa kluczowe: napawanie, warstwy wierzchnie, materiały nanostrukturalne, napawanie zrobotyzowane GMA

\section{Abstract}

The subject of the study was to analyse the influence of process parameters of robotic GMA cladding, by cored wire EnDOtec DO390N having a diameter of 1,6 mm, of cams working surfaces of coke screening plant made of Hardox 400 wear resistant steel on the quality, shape and abrasive wear resistance of test surface layers. The tests of cladding were performed by means of a welding robot Reis SRV6 and a synergic welding machine TotalArc 5000 . The test surface layers produced by the cored wire EnDOtec DO390N have iron based metallic matrix with boron carbides precipitations with a large dispersion, evenly distributed in the matrix. The size of boron carbides and the size of some phase constituents do not exceed $1,0 \mu \mathrm{m}$, and the proportion of phase constituents of such a small size in the deposited surface layers is at least $30 \%$, depending on the deposition parameters. Therefore, the deposited surface layers exhibit characteristics of nanostructured metallic material. Despite the high hardness of approx. 62 to 64 $\mathrm{HRC}$, the deposit show just slight tendency to cracking, under the applied conditions of robotized GMA cladding. The abrasive resistance metal-metal wear investigations, conducted by means of ball-on-plate test showed that the test deposited surface layers have almost seven times higher wear resistance compared to Hardox 400 steel.

Keywords: cladding, surface layers, nanostructural materials, robotic GMA cladding

\begin{abstract}
Wstęp
Nowoczesne części maszyn i urządzeń oraz narzędzia wytwarzane są często z kilku różnych materiałów metalicznych lub też kompozytowych $[1,2]$. Dodatkowo powierzchnie robocze pokrywane są warstwami lub powłokami, których
\end{abstract}

zadaniem jest zapewnienie wysokiej trwałość. Obecnie coraz większa uwaga badaczy na całym świecie skupiona jest na nanomateriałach, których cechą charakterystyczną jest wielkość ziarna w skali nanometrycznej, najczęściej w zakresie poniżej $100 \mathrm{~nm}$ [3]. Materiały tego typu posiadają ogromny potencjał, gdyż ich właściwości użytkowe (np. wytrzymałość mechaniczna, twardość) często są wielokrotnie wyższe 
od konwencjonalnych materiałów. Nawet poprzez rozdrobnienie ziarna i utworzenie nanostruktury w przypadku znanych już materiałów inżynierskich możliwa jest znaczna poprawa właściwości fizycznych, chemicznych i mechanicznych takich, jak np. wzrost twardości i wytrzymałości, wzrost odporności na zużycie powierzchni kontaktowych, wzrost ciągliwości materiałów kruchych itp. Stąd też w przemyśle rośnie zainteresowanie wytwarzaniem warstw wierzchnich z nanomateriałów jak również technologiami, które umożliwią wytworzenie warstw wierzchnich nanostrukturalnych.

\section{Przebieg badań i materiały}

Celem badań była analiza wpływu parametrów procesu zrobotyzowanego napawania GMA drutem rdzeniowym EnDOtec D0390N o średnicy 1,6 mm powierzchni roboczych krzywek przesiewacza koksu ze stali trudnościeralnej Hardox 400 [2] na jakość, kształt oraz odporność na zużycie ścierne napoin próbnych (tabl. I). Zgodnie ze specyfikacją techniczną, drut rdzeniowy EnDOtec DO390N (nano) jest specjalnym opatentowanym materiałem dodatkowym do napawania łukowego GMA o stopiwie nanometalicznym, charakteryzującym się wysoką twardością nawet do 71 HRC bezpośrednio po napawaniu i wysoką odpornością na zużycie ścierne [3]. Próby napawania wykonano za pomocą robota spawalniczego Reis SRV6 oraz synergicznego urządzenia spawalniczego TotalArc 5000 firmy Castolin (rys. 1). Na podstawie wstępnych prób napawania zrobotyzowanego drutem rdzeniowym EnDOtec D0390N o średnicy 1,6 mm stwierdzono, że poprawny kształt napoin, minimalny rozprysk oraz stabilny przebieg procesu napawania ruchem prostoliniowym zapewnia prędkość przesuwu palnika $5 \mathrm{~mm} / \mathrm{s}$ przy zastosowaniu programu napawania synergicznego nr 39, przeznaczonego do drutu D0390N, w trybie napawania łukiem pulsującym. W związku z tym napoiny próbne wykonano ze stałą prędkością napawania $(5 \mathrm{~mm} / \mathrm{s})$, lecz różnych natężeniach prądu odpowiednio $250 \mathrm{~A}$ (napoina N1 oraz N1A, rys. 2), 300 A (napoina N2, rys. 2) oraz 200 A (napoina N3, rys. 2). Napoiny próbne wykonano na płaskiej powierzchni krzywki (N1 do N3, rys. 2a) oraz na krawędzi roboczej krzywki (N1A, rys. 2a). Przed napawaniem

a)

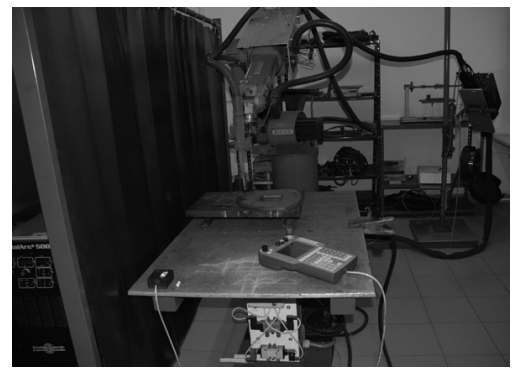

b)

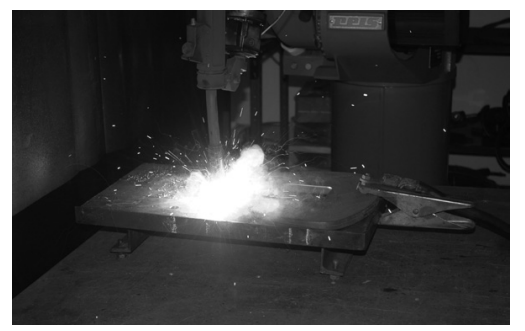

Rys. 1. Widok zrobotyzowanego stanowiska badawczego wykorzystanego do napawania krzywek przesiewacza koksu (a) oraz procesu napawania krzywki (b); 1 - urządzenie spawalnicze TotaIArc 5000, 2 - robot spawalniczy Reis SRV6, 3 - krzywka

Fig. 1. A view of robotic experimental stand used for cams cladding of coke screening plant (a) and a view of the cam cladding process; 1 - the welding device TotalArc 5000, 2 - the welding robot Reis SRV6, 3 - the cam powierzchnię krzywki czyszczono za pomocą szlifierki kątowej. Parametry oraz szczegółowe warunki technologiczne napawania przedstawiano w tablicy I. Po napawaniu wykonano badania wizualne VT, penetracyjne PT z zastosowaniem penetrantu barwnego, badania metalograficzne i obserwacje makro oraz mikroskopowe, jak również pomiary twardości HRC na powierzchni lica napoin i powierzchni krzywki oraz mikrotwardości HV0,5 na powierzchni zgładów metalograficznych. Z kolei na powierzchni lica napoin próbnych wykonano

Tablica I. Parametry napawania zrobotyzowanego GMA drutem rdzeniowym EnDOtec DO390N powierzchni krzywki przesiewacza koksu ze stali Hardox 400

Table I. Parameters of robotized GMA cladding of the cam of coke screening plant made of wear resistant steel Hardox 400 , by the cored wire EnDOtec DO390N

\begin{tabular}{|c|c|c|c|}
\hline $\begin{array}{c}\text { Napoina } \\
\text { próbna }\end{array}$ & $\begin{array}{c}\text { Nominalne* } \\
\text { natężenie } \\
\text { prądu } \\
\text { napawania [A] }\end{array}$ & $\begin{array}{c}\text { Nominalne* } \\
\text { napięcie łuku } \\
\text { [V] }\end{array}$ & $\begin{array}{c}\text { Energia linio- } \\
\text { wa napawa- } \\
\text { nia [J/cm] }\end{array}$ \\
\hline N1 (N1A) & 250,0 & 22,2 & 111,0 \\
\hline N2 & 300,0 & 24,8 & 148,8 \\
\hline N3 & 200,0 & 20,0 & 80,0 \\
\hline
\end{tabular}

Uwagi: * - napięcie łuku dostosowane do wartości nastawy nominalnego natężenia prądu według programu synergii 39 w trybie napawania łukiem pulsującym, prędkość napawania ruchem prostoliniowym $5,0 \mathrm{~mm} / \mathrm{s}$, mieszanka osłonowa M21 (Ar + $18 \% \mathrm{CO}_{2}$ ), natężenie przepływu gazu osłonowego $18 \mathrm{l} / \mathrm{min}$, napawanie bez podgrzewania wstępnego
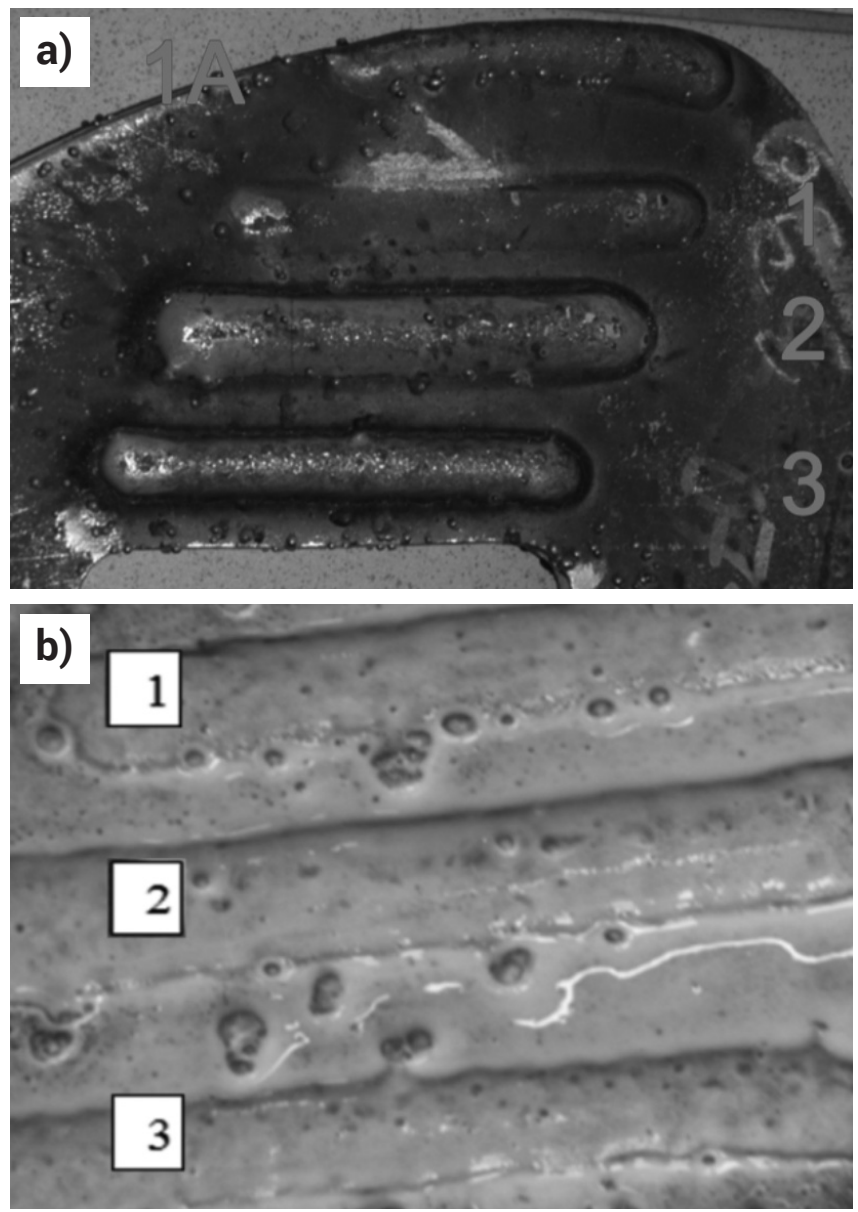

Rys. 2. Widok napoin próbnych wykonanych na powierzchni krzywki przesiewacza koksu bezpośrednio po napawaniu (a) oraz podczas badań penetracyjnych (brak pęknięć)

Fig. 2. A view of test clads produced on the surface of the cam directly after cladding (a) and during the penetrant testing (no cracks) (b) 
badania odporności na zużycie ścierne ball-on-plate za pomocą testera Tribometer CSM Instruments. Przed badaniami odporności na zużycie ścierne powierzchnię lica napoin wyrównano za pomocą szlifierki do płaszczyzn. Kulka o średnicy $6 \mathrm{~mm}$ wykonana z tlenku glinu $\left(\mathrm{Al}_{2} \mathrm{O}_{3}\right)$ była dociskana do badanej powierzchni ze stałą siłą $10 \mathrm{~N}$. Przemieszczanie kulki ruchem posuwisto-zwrotnym na odcinku $4 \mathrm{~mm}$ odbywało się z nominalną prędkością przesuwu $10 \mathrm{~mm} / \mathrm{s}$. Całkowita droga tarcia kulki (przeciwpróbki) po badanej powierzchni wynosiła $250 \mathrm{~m}$.

a)

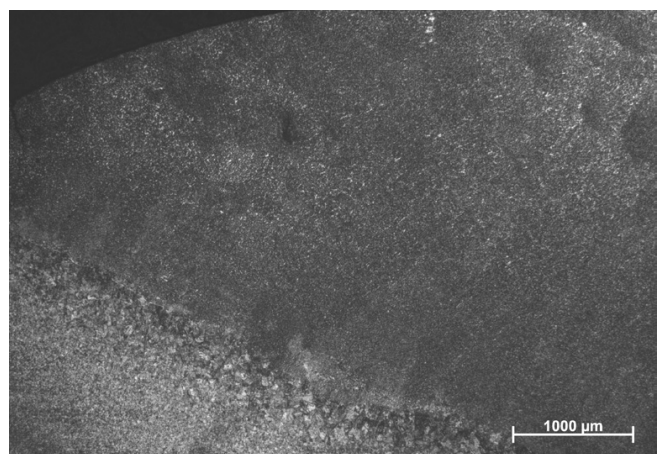

b)

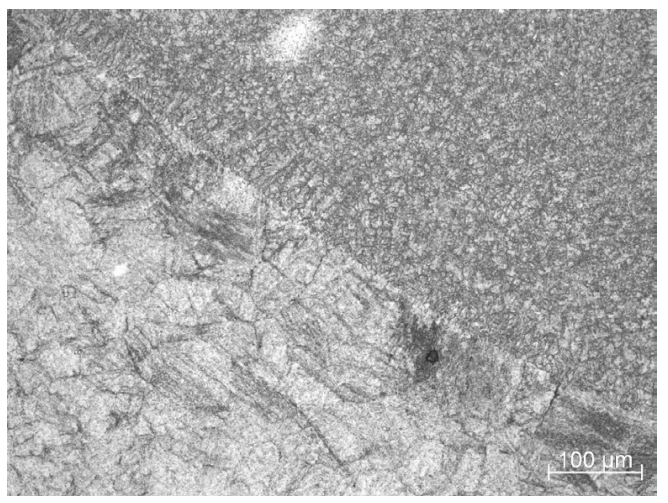

c)

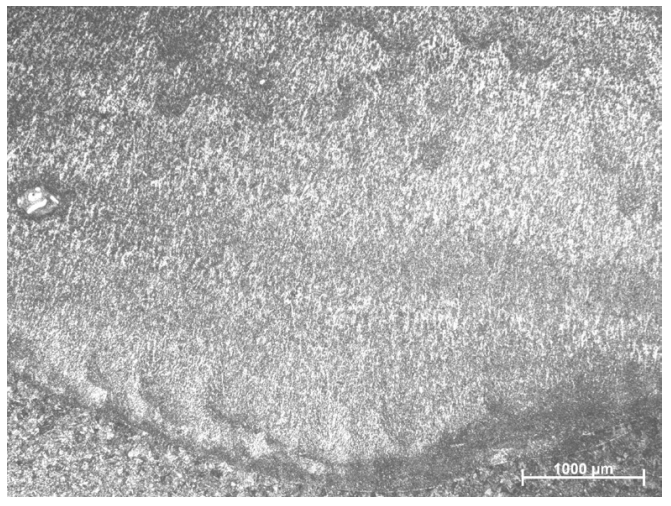

d)

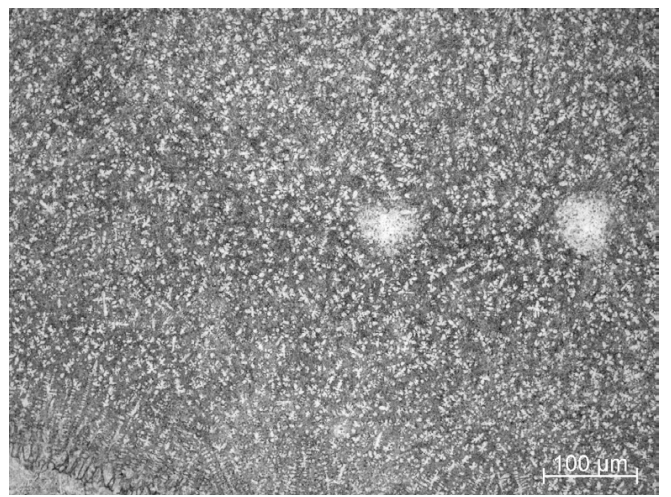

Rys. 3. Makro i mikrostruktura napoin próbnych wykonanych drutem rdzeniowym EnDOtec D0390N na powierzchni krzywki ze stali Hardox 400; a) napoina N1 (prąd napawania 250 A), b) napoina N3 (prąd napawania $200 \mathrm{~A}$ ), $\mathrm{N}$ - napoina, Lw - linia wtopienia

Fig. 3. Macro and microstructure of test clads produced by the cored wire EnDOtec DO390N on the surface of cam made of Hardox 400 steel; a) clad N1 (cladding current $250 \mathrm{~A}$ ), b) clad N3 (cladding current $200 \mathrm{~A}$ ); $\mathrm{N}$ - clad, Lw - fusion line

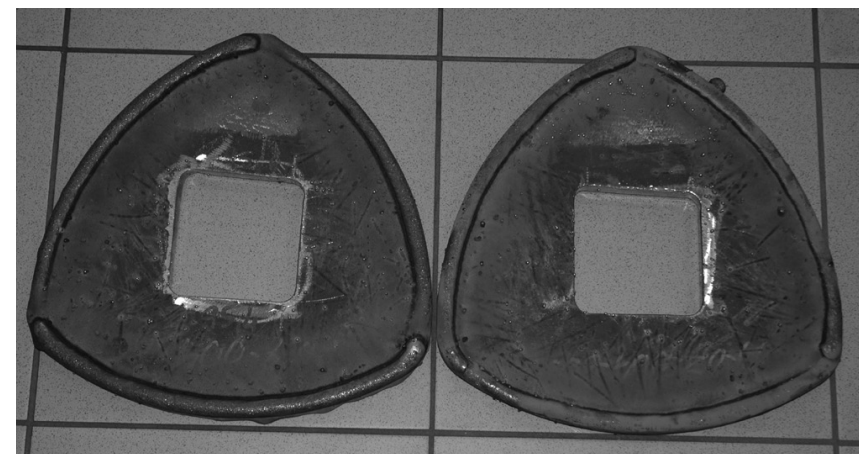

Rys. 4. Widok krzywek z powierzchniami roboczymi napawanymi drutem rdzeniowym EnDOtec DO390N

Fig. 4. A view of cams of coke screening plant with clads produced on the working surface by the cored wire EnDOtec D0390N

a)

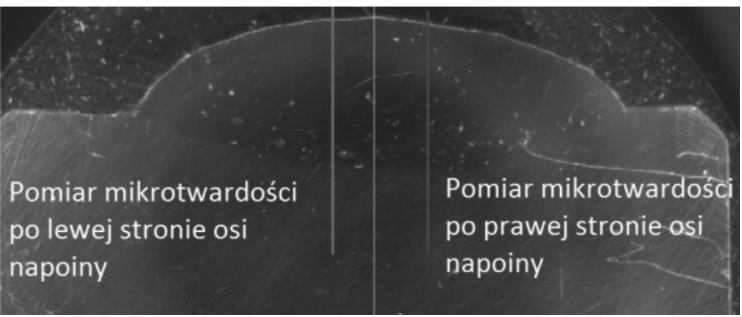

b)
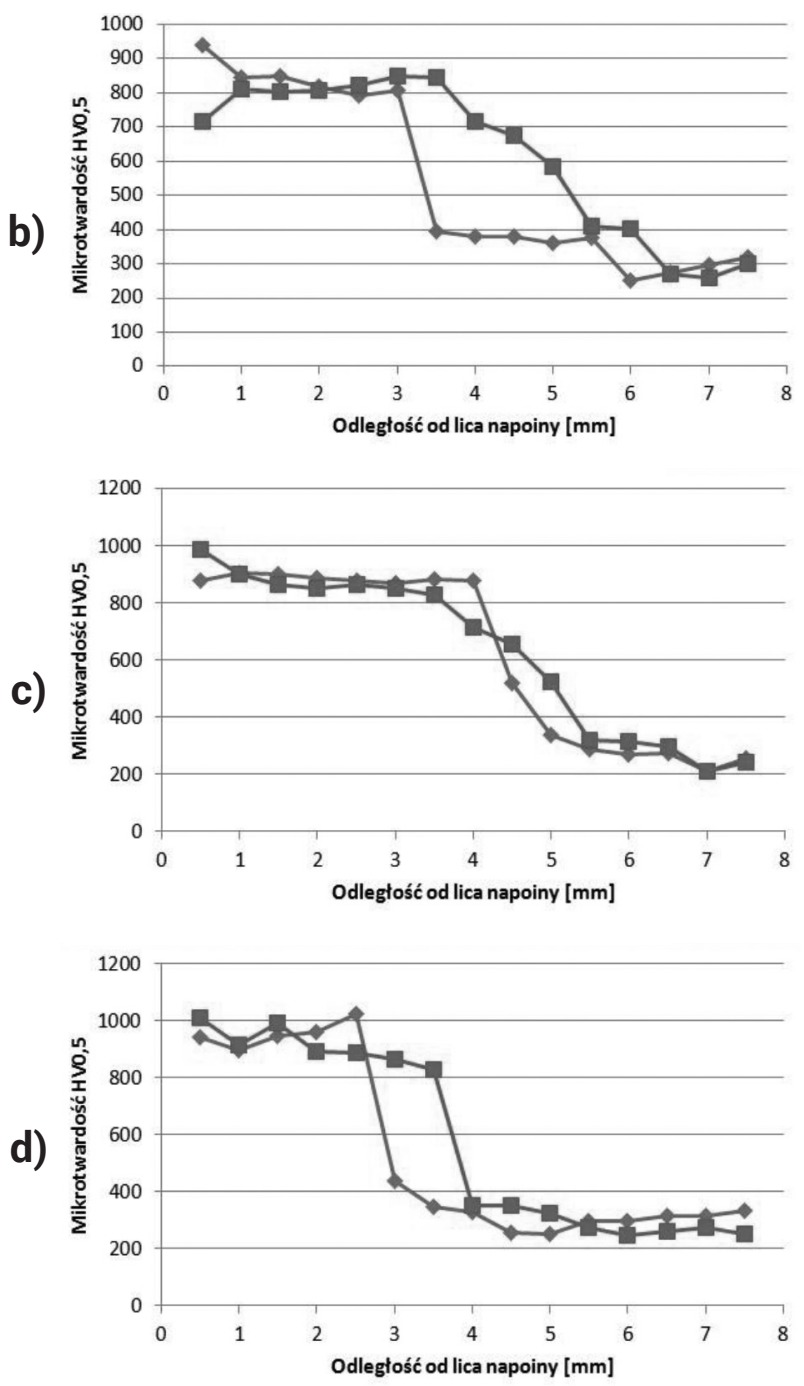

Rys. 5. Sposób pomiaru mikrotwardości na przekroju poprzecznym napoin próbnych (a) oraz rozkład mikrotwardości; b) napoina N1, c) napoina N2, d) napoina N3

Fig. 5. The method of microhardness measuring on the cross-section of test clads (a) and microhardness distribution; b) clad N1, c) clad N2, clad d) N3 
Głębokość i profil ścieżki wytarcia wyznaczono za pomocą profilometru stykowego Sutronic 25 firmy Taylor Hobson. Miarą odporności na zużycie jest objętość materiału, który uległ wytarciu (ubytek objętościowy). Ubytek materiału wyznaczono obliczając pole przekroju ścieżki wytarcia dla każdej z napoin próbnych, jak również materiału podłoża, tj. stali trudnościeralnej Hardox 400 (rys. 6, 7). Po analizie wyników badań napoin próbnych wykonano dwa komplety krzywek z napawanymi krawędziami roboczymi. Krzywki te były przeznaczone do badań eksploatacyjnych. Krawędzie napawano przy natężeniu prądu 250 A i energii liniowej $111 \mathrm{~J} / \mathrm{cm}$, co zapewniało poprawne formowanie napoiny na krawędzi roboczej krzywki, (rys. 4).

a)

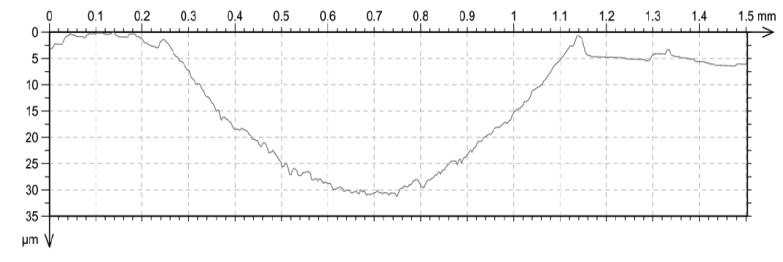

b)

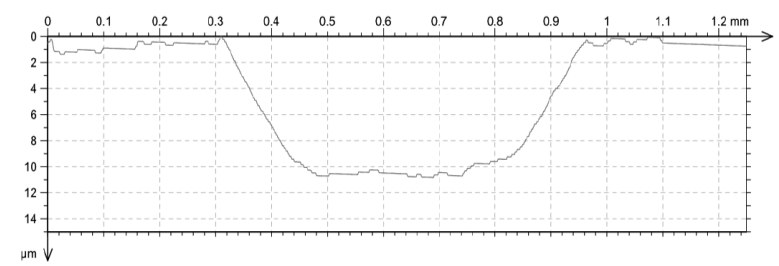

Rys. 6. Profil ścieżki wytarcia na powierzchni próbki ze stali Hardox 400 (a) oraz napoiny próbnej N3 (b)

Fig. 6. A profile of the wear track on the surface of Hardox 400 steel sample (a) and the test clad N3 (b)

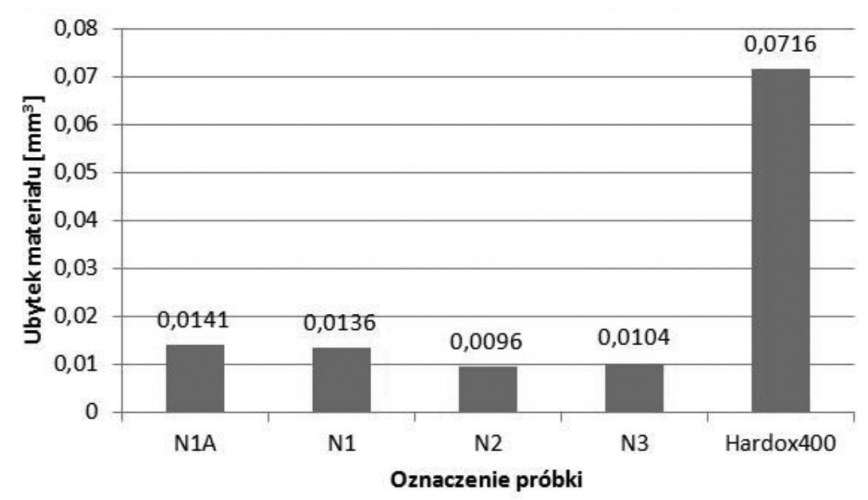

Rys. 7. Wyniki badań odporności na zużycie ścierne stali Hardox 400 oraz napoin próbnych metodą ball-on-plate

Fig. 7. The results of abrasive wear resistance study of Hardox 400 steel and the test clads determined by the ball-on-plate method

\section{Analiza wyników badań}

W wyniku badań wizualnych oraz penetracyjnych napoin próbnych wykonanych drutem rdzeniowym EnDOtec D0390N na powierzchni krzywki przesiewacza koksu ze stali trudnościeralnej Hardo 400 ujawniono jedynie dwa płytkie pęknięcia poprzeczne na powierzchni lica napoiny N1 (rys. 2). W przypadku pozostałych napoin próbnych nie stwierdzono jakichkolwiek pęknięć na powierzchni lica.

Obserwacje makro oraz mikroskopowe potwierdziły wysoką jakość napoin próbnych, gdyż nie stwierdzono jakichkolwiek pęknięć, jak i innych niezgodności spawalniczych na powierzchni przekroju poprzecznego badanych zgładów metalograficznych. Napoiny posiadają regularną, symetryczną linię wtopienia i charakteryzują się poprawnym połączeniem metalurgicznym z podłożem ze stali Hardox 400 (rys. 3). Szerokość strefy wpływu ciepła SWC napoin próbnych jest proporcjonalna do energii liniowej napawania i mieści się w zakresie od ok. 1,6 mm, w przypadku napoiny wykonanej przy najniższej energii liniowej $80 \mathrm{~J} / \mathrm{mm}$, do 2,4 mm w przypadku napoiny wykonanej przy najwyższej energii liniowej $148 \mathrm{~J} / \mathrm{cm}$. Badania metalograficzne i obserwacje mikrostruktury napoin próbnych oraz materiału rodzimego (podłoża) wykazały, że podłoże ze stali trudnościeralnej Hardox 400 posiada strukturę martenzytu odpuszczonego (rys. 3). Natomiast wzdłuż linii wtopienia napoin próbnych można wyróżnić strefę wzrostu kryształów kolumnowych i dendrytycznych, narastających prostopadle do niej, czyli zgodnie z kierunkiem najbardziej intensywnego odprowadzania ciepła w czasie krystalizacji jeziorka spawalniczego. Szerokość tej strefy wynosi od 50 do ok. $80 \mu \mathrm{m}$ w przypadku wszystkich napoin (rys. 4b i d). Z kolei w obszarze środkowym napoin próbnych struktura jest odmienna z powodu innych warunków odprowadzania ciepła, a w związku z tym innych warunków krystalizacji (rys. 4b i d). W środkowym obszarze napoiny ciepło w czasie krystalizacji metalu jest odprowadzane we wszystkich kierunkach, a gradienty temperatury są znacznie niższe w porównaniu do strefy w pobliżu linii wtopienia. W tym obszarze napoiny występują drobne równoosiowe dendryty oraz znaczna ilość wydzieleń o niewielkich rozmiarach, w większości poniżej $1 \mu \mathrm{m}$, rozłożonych równomiernie w osnowie. Bazując na informacjach podanych w specyfikacji technicznej drutu EnDOtec D0390N, jak również składzie chemicznym drutu i stopiwa, można wnioskować, że zidentyfikowane w osnowie metalicznej wydzielenia o dużej dyspersji to złożone borowęgliki powstałe w trakcie krystalizacji metalu napoiny (In situ) $[1,2]$.

W związku z tym, iż wielkość niektórych składników fazowych, jak również wydzieleń w osnowie metalicznej posiada wymiary poniżej $1 \mu \mathrm{m}$, a ich udział $w$ napoinie wynosi ok. 30\% można uznać, iż napoiny próbne wykonane drutem D0390N wykazują cechy materiału nanostrukturalnego.

Średnia twardość HRC napoin próbnych mierzona na powierzchni lica mieści się w zakresie $62 \div 64,4$, a więc jest nieco niższa, niż maksymalna wartość twardości deklarowana przez producenta drutu. Nie stwierdzono jednocześnie wyraźnego wpływu energii liniowej napawania w badanym zakresie parametrów na twardość napoin. Z kolei twardość HRC materiału podłoża, tj. stali trudnościeralnej Hardox 400 mieści się w zakresie 32,5 $\div 33,7$.

Pomiary mikrotwardości HV0,5 wykonane na powierzchni przekroju poprzecznego napoin próbnych wykazały niewielki rozrzut wyników. Mikrotwardość w obszarze napoiny utrzymuje się na stałym poziomie i mieści się w zakresie od 850 do 1020 HV0,5 (rys. 5). Z kolei w strefie wpływu ciepła następuje stopniowy spadek mikrotwardości do poziomu materiału rodzimego (Hardox 400) ok. 300 HV0,5 (rys. 5).

Badania odporności na zużycie ścierne wykonane metodą ball-on-plate wykazały, że napoiny próbne posiadają wyraźnie wyższą odporność w porównaniu do stali trudnościeralnej Hardox 400. Odporność na zużycie ścierne określono na podstawie wyznaczonych ubytków objętości materiału w wyniku próby ścierania. W przypadku próbki ze stali Hardox 400 szerokość ścieżki wytarcia była równa ok. 0,9 mm, przy średniej głębokości równej $30 \mu \mathrm{m}$ (rys. 6). W tym przypadku ubytek materiału był równy $0,0716 \mathrm{~mm}^{3}$ (rys. 7). Natomiast $\mathrm{w}$ przypadku napoin próbnych szerokość ścieżki wytarcia nie przekraczała 0,63 mm, a głębokość wytarcia była nie większa niż $10 \mu \mathrm{m}$ (rys. 6). Ubytek materiału napoin próbnych mieścił się w zakresie od 0,0096 do 0,0141 $\mathrm{mm}^{3}$, najwyższą odporność na zużycie wykazała napoina N2 wykonana przy najwyższej energii liniowej $148 \mathrm{~J} / \mathrm{cm}$ (rys. 7). 


\section{Podsumowanie}

Wyniki badań napoin próbnych wykonanych drutem EnDOtec D0390N na powierzchni krzywki przesiewacza koksu ze stali Hardox 400 wykazały, że napoiny wykazują cechy materiału metalicznego nanostrukturalnego, gdyż wielkość niektórych składników fazowych jest poniżej $1 \mu \mathrm{m}$, a udział tych drobnych faz w napoinie wynosi co najmniej $30 \%$. Napoiny próbne posiadają wysoką twardość rzędu $62 \div 64 \mathrm{HRC}$, a odporność na zużycie ścierne napoin jest kilkakrotnie wyższa od stali trudnościeralnej Hardox 400.

\section{Literatura}

[1] A. Lisiecki, A. Majowski, T. Gorzelik, J. Jarek, P. Gorzela, A. Kurc-Lisiecka, „Sterowanie jakością i trwałością części roboczych brykieciarki napawanych metodą MMA w procesie wytwarzania brykietów stalo-

[2] http://www.steelpro.co.uk/pdf/HARDOX_400_UK.pdf. napawanych metodą MMA w procesie wytwarzania bryki 